\title{
Learning Disabilities: Characteristics and Instructional Approaches
}

\author{
Mrs. Sana Ali \\ Research Scholar,Education, Mewar University, Rajasthan \\ India, Lecture, University of Dammam, K.S.A \\ Dr. Mohammed Rafi \\ Head/Professor, Education, Al-Madina College of Education \\ Mahboob Nagar District, Telangana,India
}

\begin{abstract}
A learning disability is a neurological disorder. In simple terms, a learning disability results from a difference in the way a person's brain is "wired." Children with learning disabilities are smart as or smarter than their peers. But they may have difficulty reading, writing, spelling, reasoning and organizing information if left to figure things out by them or if taught in conventional ways. A learning disability can't be cured or fixed; it is a lifelong issue. With the right support and intervention, however, children with learning disabilities can succeed in school and go on to successful, often distinguished careers later in life. Parents can help children with learning disabilities achieve such success by encouraging their strengths, knowing their weaknesses, understanding the educational system, working with professionals and learning about strategies for dealing with specific difficulties.The Individuals with Disabilities Education Act (IDEA), a federal law, defines a learning disability as a condition when a child's achievement is substantially below what one might expect for that child. Learning disabilities do not include problems that are primarily the result of intellectual disabilities, emotional disturbance, or visual, hearing, emotional or intellectual disabilities.
\end{abstract}

Ke ywords:Learning Disability, Children, Reading, Right Support, Parents, IDEA

\section{INTRODUCTION TO THE CONCEPT OF LEARNING DISABILITY}

The definitions given by various authors suggest that learning disability refers to a retardation, disorder,or delayed development in any one or more of the processes of speech, language, reading, spelling, writing, or arithmetic. These problems are due to disorder or deficiency in any one or more of the basic psychological processes involved in understanding or in use of spoken or written language. They do not include learning problems which are due primarily to visual,hearing or motor handicaps, mental retardation, and emotional disturbance or to adverse environmental factors. The child ,thus can be considered as learning disabled if,(1)he has considerable difficulty in understanding or using spoken language,reading,writing,spelling,and arithmetic,during the developmental period (before 16 years of age),(ii) he has adequate facilities, interest and motivation to learn( Ramaa, 1992). According to government regulations, students with learning disabilities have "disorders in one or more basic psychological processes involved in understanding or using language, spoken or written, which may manifest itself in an imperfect ability to listen, think, speak, read, write, spell or do mathematical calculations. "There are many different kinds of learning disabilities. Most often they fall into three broad categories:

Reading disabilities (often referred to as dyslexia)

Written language disabilities (often referred to as dysgraphia)

Math disabilities (often called dyscalculia)

\subsection{Ge neral Characte ris tics of Learning Disabled Student}

The learning disabled students exhibit certain general characteristics features, the knowledge of which is essential in identifying them at the very early stage and understand the difficulties faced by such children.Below is given a list of the general characteristics features of learning disabled children.(Ramaa, 1992) 


\section{AbNormal ACTIVITy LeVEL}

Hyperactive: constantly engaged in some form of unnecessary motor activity.Hypoactive-Fails to react to environmental changes or seems to do everything in slow motion.

Attention:Short attention span-easily distracted by what is going on in the surrounding.PerseverationAttention becomes fixed upon a single task,difficulty in changing mental set.

Motor Problems:Inadequate coordination -Lack of adequate gross and fine coordination.Poor Tactile -Kinesthetic discrimination-Has difficulty in discriminating shapes,textures size only through touching,lack adequate visual-motor memory.

\section{Vis ual Perceptual Problems}

Poor visual discrimination- Unable to distinguish between visual stimuli through seeing them.Difficulty in visual closure-Cannot fill in missing parts when only part of the word or Object is seen. Poor visual memory, visual recognition, recall and sequential memory are deficient.

\section{Auditory Perceptual Problems}

Poor auditory discrimination-unable to distinguish one sound from another. Poor Auditory reception/Comprehension-Unable to gain meaning from sounds, words,sentences.Difficulty in Auditory figure ground differentiation-Unable to attend to important auditory stimuli into the background.Difficulty in Auditory Closure- Cannot fill in missing sounds when only part of the word/sentence is heard.Deficiency in Auditory Memory-Poor Auditory recognition,recall and sequential memory.

\section{Language Problems}

Delayed or slow development of speech. Difficulty in formulation and syntax-unable to organize words to form phrases, clauses or sentences in the appropriate way.

\section{Faculty Work Habits}

May organize work poorly, work slowly,frequently confuse directions or rush through work carelessly.

\section{Social -Emotional behavioral problems}

Impulsive,explosive,inadequate social competence, difficulty in adjusting to changes,drastic,change in mood are noticed.

\section{Orientation Problems}

Inadequate spatial organization-Poorly developed concept of space.

Inadequate temporal concepts-Disoriented in time.

\section{Academic Disabilities}

Problems in reading, writing spelling and arithmetic. Every learning disabled child does not exhibit all the above characteristics, rather each demonstrate a unique combination of these characteristics. Depending upon the combination they experience different kinds of learning disabilities. In order to understand the difficulties experienced by the learning disabled an attempt has been made below to elaborate the characteristics observed in them certain areas.

\section{LANGUAge Characteristics}

The specific difficulties noticed by LD students (Thomas, 1989) in the area of language are discussed here:

\section{Cognitive Deficiencies}

Auditory-Symbolic Units (Speech sounds): The ability to derive word structure from auditory stimuli constitute their ability to comprehend or use those units. LD students often have problems in auditory perception which can be noticed in difficulty in sound blending.

Semantic Units (Words and Concepts): Individual words may be classified into groups or semantic classes according to some criteria.The ability to name the class name (super ordinate)when given names of class members constitute one feature of understanding classes, and the ability to name class members when experience difficulty in both forms of classification. 
Semantic relations (Word Relationships): LD youngsters have difficulty in understanding the underlying sequences when presented with such relations as comparison,spatial,temporal,familial relationships.

Semantic systems(word problems): In order to solve verbal problems, understanding the inherent relations in the problem and the processes involved in solving it are necessary, many LD children have difficulties in reading comprehension and in mathematical,spatial and temporal reasoning.

Semantic transformations (changes in meaning): The information transmitted by any word may vary,depending upon the context, role of significance of the utterance. The recognition of and ability to make changes in meanings of words reflected an understanding of semantic transformations (Wiig\& Semel,1984)Majority of LD children have difficulty in processing multiple meaning words,idioms and metaphors.

Semantic Implications (Implied meaning)-Considerable number of Ld.Individuals have difficulty in Understanding fables, myths and proverbs.

\section{Language Productiondeficiencies.}

According to Wiig andSemel (1984) language production may be facilitated by memory and retrieval as well as by affective behaviors (such as ideas,practices,standards,values) and psychomotor behaviors (sensory perception and mental, physical and emotional set.)As LD youngsters are deficient in these aspects their language is adversely affected.

Convergent Production Abilities- Ld students may exhibit deficits in this area. Their rate and accuracy on naming pictured objects or event and verbal opposites,completing verbal analogies,completing sentences and redefining words and concepts are lower than that of non LD youngsters.

Divergent Production abilities-The fluency, flexibility,originality and elaboration with which language is produced constitute a person's divergent semantic abilities.Divergent production abilities are involved in the following tasks:

- Naming words and concepts

- Completing verbal associations and analogies.

- Formulating ideas and verbal problems

- Reformulating ideas and verbal problems

- Reformulating concepts and ideas

- Formulating alternatives and solutions

According to Wiig and Semel(1984)Ld. youngsters have relative strength in divergent production abilities.However,specific deficit was noticed in the rate and accuracy with which they name specific units.

\section{Deficiencies in Pragmatic Areas (Functional use of Language)}

Bryan,Donohue and pearl (1981)have noticed that LD children demonstrate more difficulty than non -Ld. students in such skills as asking questions, responding to inadequate messages,sustaining a conversation,disagreeing with and supporting an argument.

\section{Social Competence ANd Motivational Characteristics of Learning DisAbled STUDENTS}

Unlike the categories of mental retardation and behavioral disorders,learning disability is defined exclusively in terms of Academic incompetence.Only recently, a number of researchers and educators started showing interest in the social competence characteristics of LD students. The reason for such an interest is that students with LD are often poorly acceptedby peers and consistently exhibit deficits in positive social behaviors relative to their non - LD counterparts (Gresham,1988)

Gresham (1988) believes that identification and remediation of social skill deficiencies as wellas enhancing the acceptance of LD students by peers and teachers and teachers are the critical aspects of an appropriate education to such children. Learning disabled students exhibit the following social characteristics. 
- less able to predict the consequences for their behavior.

- misinterpret social cues more often, able to adapt their behaviors to the characteristics of their listeners,perform certain inappropriate social behaviors at significantly higher levels.

- get low social status scores,less preferred by teachers than non-LD students.

- Lower than the normative samples in their participation in activities,social involvement and their performance in school.

- Exhibit more immaturity, hostility -withdrawal aggressiveness, and hypersensitivity indicating severe behavior disturbance.

- poorer in giving positive feedback, giving negative feedback,accepting negative feedback,resisting peer pressure, negotiating conflict situations, followinginstructions,carrying on conversations and solving personal problems, in empathy.

- More negative conscious and unconscious self-concepts-higher anxiety levels,more negative perceptions of their intellectual abilities, school status and popularity,and more feelings of insecurity,inadequacy,guilt,impulsivity and immaturity.-believe that their intellectual,academic and physical characteristics are significantly inferior to those of their non-LD mates.

- less friendly in comparison with non LD mates.

The theories of reflectance motivation,learned helplessness,self-efficacy, operant learning or ecological behavioral analysis adequately explain the social deficits of LD students. (Gresham, 1988).

\section{INSTRUCTIONAL APPROACHES FOR LD YOUTH}

A number of instructional approaches for LD youth and others cut across several subjects (for example reading,writing,mathematics,language,science,social studies,etc.)And they are applicable for students at both elementary and secondary levels. The premise of each such strategiesand the important principles involved in those strategies (Thomas, 1988) are summarized below.

Cognitive Training:This involves the training of metacognition skills. Knowledge of cognitive resources and the use of self-regulatory mechanics such as planning strategies,monitoring their effectiveness and evaluating those strategies. This approach focuses on attending, reading,vocabulary writing,spelling and mathematics.

Self-Management Instruction:The approach aims at training the students in the three components: Self -recording (including counting and charting), self-evaluating (comparing one's performance to a standard, or commenting on the quality of the performance), self-selecting interventions,schedules, reinforces contingencies and goals.)A number of studies have arranged multiple components of self -management .Four interrelated phases were involved in the project by Tolefson,Tracy,Johnson and Chatman (19860to each self -regulation.

- Setting realistic academic goals,

- Developing plans to reach those goals,

- Implementing the plans,monitoring progress toward the academic goals, and evaluating progress towards the academic goals,and evaluating progress by personal standards.

- To achieve positive interdependence among group members, goals are structured so that the students need to be concerned about the performance of all group members as well as their individual performances.

- Individuals accountability is achieved through assessment of every student's mastery of the assigned material and giving feed back to the individual as well as to the group.

- The group is typically heterogeneous in terms of ability and personality characteristics.

- Each member should act as leaders in turn.

- Members share responsibility in improving learning of all the members to the maximum through help and encouragement.

- The goals focus on maintaining good working relationship among members. 
- The collaborative skills are directly taught to the students.

- The teacher supervises the group and guides the members to perform the group tasks.

- The teacher structures procedures for groups to evaluate the way in which the group works.

Tutoring: Tutoring means one person is assigned to one teacher. Tutoring has advantages as follows

- Increases the time tutees spend on tasks.

- Increase the number of opportunities for tutees to respond and,correspondingly, the amount of feedback and reinforcement they get.

- Allow tutees to work with pupils who may in some respects be good models.

- Facilitate socialization between tutor and tutees.

- Aid tutors to acquire information on the subjects they are tutoring.

- Raise the esteem of tutors, either non-handicapped or handicapped.

The practices that are outlined above are all interrelated.Decision regarding the approached should be based on the important objectives of teaching a particular lesson,scope for cooperative learning,type of content to be learnt, availability of time and other resources.

\section{CONCLUSION}

Some individuals, despite having an average or above average level of intelligence, have real difficulty acquiring basic academic skills. These skills include those needed for successful reading, writing, listening, speaking and/or math. These difficulties might be the result of a learning disability. There are different strategies to solve the problems of learning disabled children. These strategies are successfully implemented with the help of parents and teachers. We want to concludethat through this paper we have explained the concept of learning disability, characteristics of learning disability, instructional approaches and strategies to improve/ solve the problems of learning disabled children.

\section{REFERENCES}

[1] Deshler,D.D and Schumaker,J.B.(1986)Learning strategies:an instructional alternative for lowachieving adolescents.Exceptional Children, 52,583-590.

[2] 2.Bryan,T.H. ,Donahue,M.and pearl,R.91981)Learning disabled children's peer interactions during a small-group problem solving task, learning disability Quaterly,4(1),13-22.

[3] Gresham, Frank (1988) Social competenceand motivational characteristics of learning disabled students. In Margaret C.Wing et al (Eds) Handbook of special education:Research and practice, Vol.2.Advances in Education,Pergamon press.

[4] Licht,B.G.(1983)Cognitive - motivational factors that contribute to the achievement of Learning disabled children.Journal of Learning Disabilities, 16,483-490.

[5] Ramaa, s.91992) Handbook on Learning Disabilities.Regional college of Education (NCERT)

[6] Thomas C. Lovitt 91989) learning Disabilities.Allyn and Bacon.

[7] Tollefson,N.,Tracy,D.B.,Johson, E.P.and Chatman,J.(1986)Teaching learning disabled students goal implementation skills.Psychology in the schools, 23,194-204.

[8] Wiig,E,H and Semel,E. (1984) Language assessment and intervention for the learning disabled child,2 ndEd. Columbus,OH: Merrill. 